\title{
156
}

\section{IDENTIFICAZIONE DELLA RESISTENZA ALLA VANCOMICINA NEGLI ENTEROCOCCHI CON SISTEMA URO-QUICK}

\author{
Roveta S., Marchese A., Debbia E.A. \\ Sezione di Microbiologia - DISCAT, Università di Genova, \\ Largo R. Benzi 10, 16132 Genova
}

Introduzione L'Uro-Quick, strumento utilizzato per lo screening della batteriuria, è stato recentemente impiegato per l'esecuzione rapida di antibiogrammi direttamente su campioni di urina (Debbia et al., Microb. Med. 19: 376-380, 2004). In questo studio sono state messe a punto le condizioni ottimali (terreno di coltura, concentrazione di antibiotico, tempo di incubazione) per l'identificazione tramite sistema Uro-Quick della resistenza alla Vancomicina in ceppi di Enterococcus spp.

Metodi Il sistema Uro-Quick utilizza una cuvetta contenente brodo (Mueller-Hinton o Brain-Heart da soli o addizionati con $\mathrm{NaCl} 2 \%$ ) in cui vengono introdotti il campione (inoculo standard: $0.1 \mathrm{ml}, 10^{6}$ cell $/ \mathrm{ml}$ ) e la vancomicina ( 4 o 10 $\mathrm{mg} / \mathrm{l})$. Una cuvetta priva di farmaco costituisce il controllo. Dopo incubazione adeguata (5, 8 o 18 ore) lo strumento interpreta i risultati: assenza di crescita/curva di crescita uguale al controllo rappresentano rispettivamente ceppo sensibile/ resistente.

Sono stati analizzati 50 ceppi di Enterococcus spp. sensibili alla vancomicina (con MIC compresa tra 1 e $2 \mathrm{mg} / \mathrm{l}$ ) e 59 ceppi resistenti (ben caratterizzati per la presenza dei geni VanA, VanB, con MIC $\geq 128$ mg/l). E. faecalis ATCC 29212 è stato usato come controllo di qualità.

Risultati Tutti i ceppi resistenti sono stati correttamente individuati dal sistema Uro-Quick dopo solamente 8 ore di incubazione utilizzando terreno $\mathrm{BH}$ (indipendentemente dalla presenza di sale) e vancomicina $4 \mathrm{mg} / \mathrm{l}$. Uro-Quick ha fornito letture corrette su tutti i ceppi sensibili alla vancomicina in tutte le condizioni sperimentali: sia con $\mathrm{MH}$ che $\mathrm{BH}$, con o senza $\mathrm{NaCl}$, con entrambi le concentrazioni di antibio- 
tico e a tutti e 3 i tempi di incubazione impostati.

Conclusioni Dal momento che sono stati ottenuti risultati corretti entro 8 ore nel $100 \%$ dei casi impiegando le suddette condizioni sperimentali (terreno $\mathrm{BH}$, vancomicina $4 \mathrm{mg} / \mathrm{l}$ ), il sistema Uro-Quick appare utile per l'identificazione rapida della resistenza alla vancomicina negli enterococchi. 